\title{
An Outbreak in Pigeons Caused by the Subgenotype VI.2.1.2 of Newcastle Disease Virus in Brazil
}

\author{
Luciano M. Thomazelli ${ }^{1}{ }^{\mathbb{D}}$, Juliana A. Sinhorini ${ }^{2}$, Danielle B. L. Oliveira ${ }^{1,3}{ }^{\mathbb{D}}$, Terezinha Knöbl ${ }^{4}$, \\ Tatiana C. M. Bosqueiro ${ }^{2}$, Elder Sano ${ }^{1,2}$, Gladyston C. V. Costa ${ }^{2}$, Cairo Monteiro ${ }^{1}$, Erick G. Dorlass ${ }^{1}$, \\ Nathalia Utecht ${ }^{1}$, Guilherme P. Scagion ${ }^{1}$, Carla Meneguin ${ }^{1}$, Laura M. N. Silva ${ }^{5}$, Maria Vitória S. Moraes ${ }^{5}$, \\ Larissa M. Bueno ${ }^{6}$, Dilmara Reischak ${ }^{7} \mathbb{1}$, Adriano O. T. Carrasco ${ }^{8}$, Clarice W. Arns ${ }^{9}$, Helena L. Ferreira ${ }^{5,6, *(\mathbb{C})}$ \\ and Edison L. Durigon ${ }^{1} \mathbb{D}$
}

Citation: Thomazelli, L.M.; Sinhorini, J.A.; Oliveira, D.B.L.; Knöbl, T.; Bosqueiro, T.C.M.; Sano, E.; Costa, G.C.V.; Monteiro, C.; Dorlass, E.G.; Utecht, N.; et al. An Outbreak in Pigeons Caused by the Subgenotype VI.2.1.2 of Newcastle Disease Virus in Brazil. Viruses 2021, 13, 2446. https:/ / doi.org/10.3390/v13122446

Academic Editors: Fabrício

S. Campos, Luciana Barros de Arruda and Maite F.S. Vaslin

Received: 26 October 2021

Accepted: 1 December 2021

Published: 6 December 2021

Publisher's Note: MDPI stays neutral with regard to jurisdictional claims in published maps and institutional affiliations.

Copyright: (c) 2021 by the authors. Licensee MDPI, Basel, Switzerland. This article is an open access article distributed under the terms and conditions of the Creative Commons Attribution (CC BY) license (https:/ / creativecommons.org/licenses/by/ $4.0 /)$.
1 Biomedical Science Institute, University of São Paulo, São Paulo 05508-000, Brazil; lucmt@usp.br (L.M.T.); danibruna@gmail.com (D.B.L.O.); elderpereira@prefeitura.sp.gov.br (E.S.); cairomonteiro00@gmail.com (C.M.); erickgd@usp.br (E.G.D.); nathalia.utecht@gmail.com (N.U.); gui.scagion@gmail.com (G.P.S.); carla.barbosa@usp.br (C.M.); eldurigo@usp.br (E.L.D.)

2 Zoonoses Surveillance Division of the Health Surveillance Coordination, Health Department of São Paulo, R. Santa Eulália, 86, São Paulo 02031-020, Brazil; janaya@prefeitura.sp.gov.br (J.A.S.); tcmoreira@prefeitura.sp.gov.br (T.C.M.B.); gccosta@prefeitura.sp.gov.br (G.C.V.C.)

3 Hospital Israelita Albert Einstein, São Paulo 05652-900, Brazil

4 Avian Medicine Laboratory, Veterinary Medicine and Animal Science School, University of São Paulo, Butantã, São Paulo 05508-270, Brazil; tknobl@usp.br

5 Graduate Program in Experimental Epidemiology Applied to Zoonoses, Veterinary Medicine and Animal Science School, University of São Paulo, São Paulo 05508-270, Brazil; lauramonasc@usp.br (L.M.N.S.); mariavitoriamoraes@usp.br (M.V.S.M.)

6 Department of Veterinary Medicine, FZEA-USP, University of Sao Paulo, Pirassununga 13635-900, Brazil; buenolm@usp.br

7 Federal Laboratory for Agricultural Defense in Sao Paulo (LFDA-SP), Animal Diagnostics Unit, Rua Raul Ferrari, s/n , Campinas 13100-105, Brazil; dilmara.reischak@agricultura.gov.br

8 Department of Veterinary Medicine, State University of the Midwest, Alameda Élio Antonio Dalla Vecchia, 838, Guarapuava 85040-167, Brazil; adriano.carrasco@gmail.com

9 Department of Genetics, Evolution and Bioagents, Institute of Biology, University of Campinas-UNICAMP, P.O. Box 6109, Campinas 13083-970, Brazil; clarns@gmail.com

* Correspondence: hlage@usp.br; Tel.: +55-19-3565-4385

Abstract: Newcastle disease virus (NDV) can infect over 250 bird species with variable pathogenicity; it can also infect humans in rare cases. The present study investigated an outbreak in feral pigeons in São Paulo city, Brazil, in 2019. Affected birds displayed neurological signs, and hemorrhages were observed in different tissues. Histopathology changes with infiltration of mononuclear inflammatory cells were also found in the brain, kidney, proventriculus, heart, and spleen. NDV staining was detected by immunohistochemistry. Twenty-seven out of thirty-four tested samples (swabs and tissues) were positive for Newcastle disease virus by RT-qPCR test, targeting the $\mathrm{M}$ gene. One isolate, obtained from a pool of positive swab samples, was characterized by the intracerebral pathogenicity index (ICPI) and the hemagglutination inhibition (HI) tests. This isolate had an ICPI of 0.99 , confirming a virulent NDV strain. The monoclonal antibody $617 / 161$, which recognizes a distinct epitope in pigeon NDV strains, inhibited the isolate with an HI titer of 512. A complete genome of NDV was obtained using next-generation sequencing. Phylogenetic analysis based on the complete CDS F gene grouped the detected isolate with other viruses from subgenotype VI.2.1.2, class II, including one previously reported in Southern Brazil in 2014. This study reports a comprehensive characterization of the subgenotype VI.2.1.2, which seems to have been circulating in Brazilian urban areas since 2014. Due to the zoonotic risk of NDV, virus surveillance in feral pigeons should also be systematically performed in urban areas.

Keywords: pigeon; urban; Newcastle disease virus; avian paramyxovirus 


\section{Introduction}

Avian orthoavulavirus 1, also known as avian paramyxovirus serotype 1 (APMV-1) or Newcastle disease virus (NDV), belongs to the genus Orthoavulavirus of the family Paramyxoviridae [1]. NDV is classified into two distinct classes, class I and II, all within a single serotype [2]. Class II viruses have a great genetic diversity, with further classification into 20 genotypes, and they are found in domestic and wild birds [3]. These viruses have infected over 250 bird species with variable pathogenicity [4]. The World Organization of Animal Health (OIE) defines the virulent NDV (vNDV) isolates as those with intracerebral pathogenicity index values of over 0.7 and the F protein cleavage site containing the amino acid motif characteristic of virulence in chickens [5]. NDV outbreaks are controlled by live attenuated, inactivated, and recombinant vaccines in the poultry industry [6].

Some vNDV isolates of genotype VI, which are recognized by a unique monoclonal antibody $(\mathrm{MAb})$ binding profile [7], have wild and domestic birds of the family Columbidae as their reservoir [8]. They are also known as pigeon paramyxoviruses 1 (PPMV-1) as they cause neurological disorders with high mortality rates when they infect these hosts [9]. First emerging in the Middle East in the late 1970s, PPMV-1 has been found worldwide [9-12]. Although PPMV-1 isolates meet the OIE criteria for vNDV, they have lower pathogenicity and transmissibility in chickens [13]. Some studies suggest that PPMV-1 can increase in pathogenicity in chickens after successive passages [14].

In rare cases, vaccinal and virulent NDV strains can cause clinical signs in humans, such as unilateral or bilateral conjunctivitis, lachrymation, or edema of eyelids. The infections are usually transient, and the cornea is not affected [4]. However, acute keratoconjunctivitis caused by coinfection with NDV and human adenovirus was recently reported [15]. Fatal pneumonia caused by infection with PPMV-1 in immunocompromised patients, likely infected from pigeons or doves, was also documented in the USA and the Netherlands [16,17]. Therefore, surveillance of NDV needs to be carried out in poultry farms and in urban environments. The present study reports an outbreak of feral pigeons located in Sao Paulo, one of the world's largest cities.

\section{Case Report}

During the Brazilian winter of 2019 (July to September), over 58 feral pigeons (Columba livia) died, and 25 were collected in São Paulo city by the Zoonoses Surveillance Division (DVZ) of the Health Surveillance Coordination, São Paulo Municipal Health Department. Sample collection, virus characterization, and virus isolation were approved by and performed following the Institutional Animal Care and Use Committee (IACUC) (CEUAFZEA-USP: 1355190521 and CEUA-ICB-USP113/2017).

Two out of twenty-five pigeons were selected for histopathology and sent to the avian medicine laboratory, Veterinary Medicine and Animal Science School, University of São Paulo (FMVZ-USP). Collected tissues were prepared for histopathology and immunohistochemistry (IHC), as previously described (Dimitrov et al., 2019), with few modifications. A 1:100 dilution of a primary polyclonal rabbit-derived anti-NDV La Sota strain (BS-10044R, Thermo Fisher, Waltham, MA, USA) was applied and allowed to incubate overnight at $4{ }^{\circ} \mathrm{C}$. The primary antibody was then detected by using the EasyLink's one anti-immunoglobulin kit with an HRP detection system (Grupo Erviegas, Indaiatuba, Brazil). DAB (Thermo Fisher, USA) served as the substrate chromogen, and hematoxylin was used as a counterstain. Pigeons showed neurological signs, including prostration, disorientation, incoordination, opisthotonos, wing paralysis, and regurgitation of liquid content. In most birds, lung congestion, diffuse hepatitis, mild necrosis, and hemorrhages in the pancreas, duodenum, and brain were present. Histopathological changes were observed in different tissues from infected pigeons. The infiltration of mononuclear cells was observed in many tissues, such as the kidney, heart, brain, intestine, and proventriculus. NDV protein antigen staining was detected in intracytoplasmic and extracellular areas of necrosis neurons in the brain and mucous membrane cells of the tertiary duct in the proventriculus (Figure 1). 

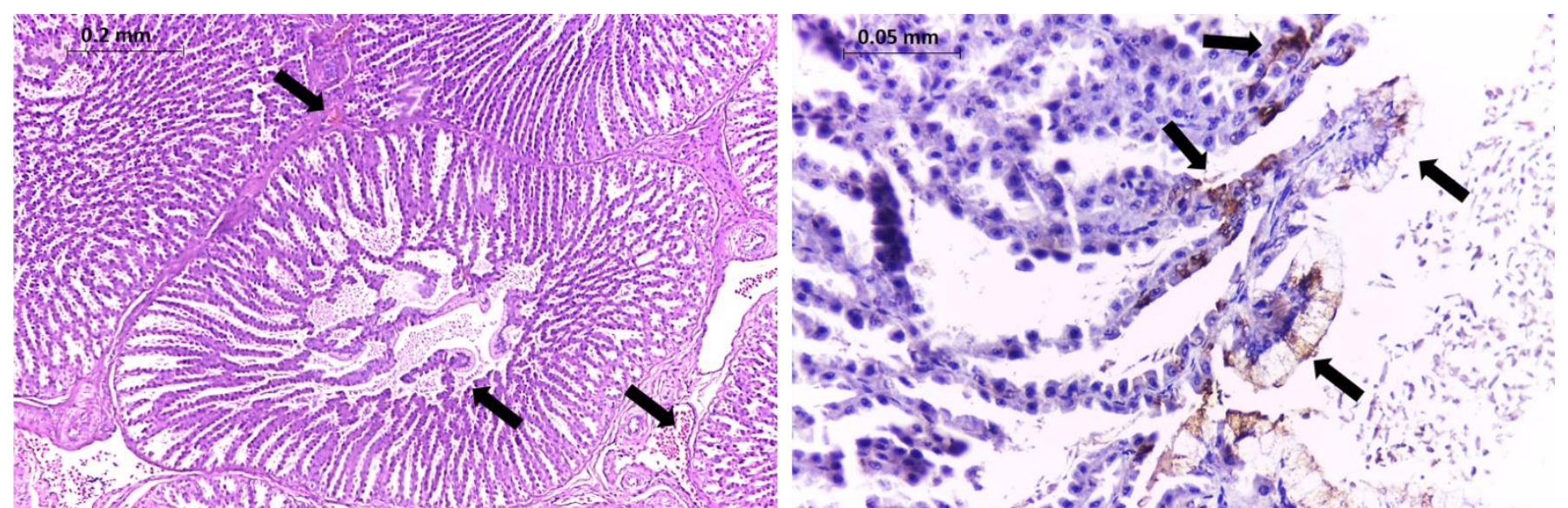

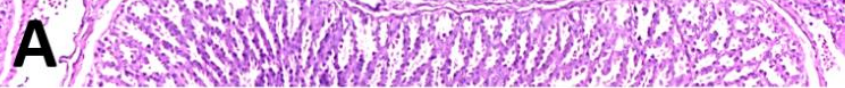
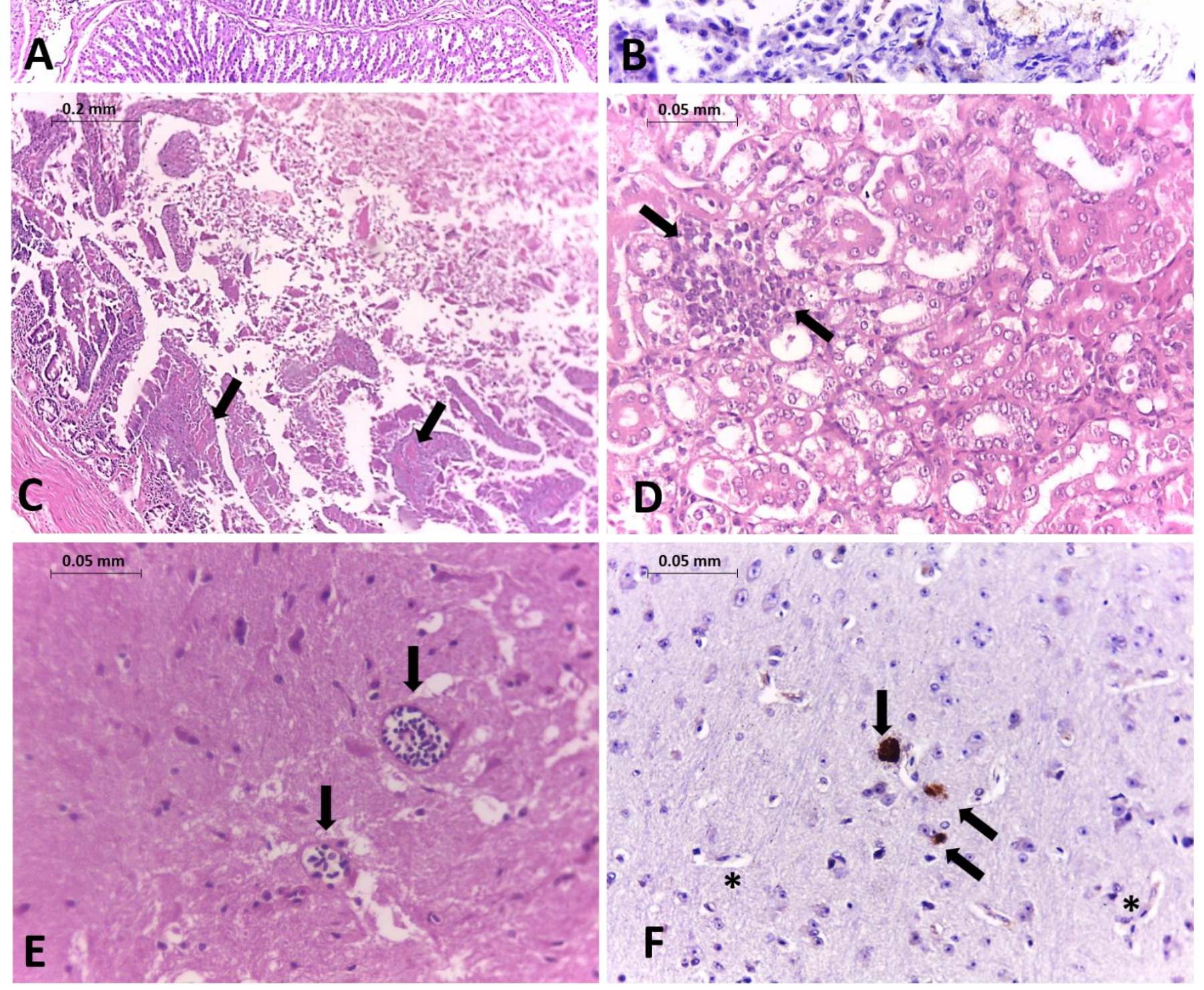

Figure 1. Histopathology changes and immunohistochemistry (IHC) in tissues from a naturally infected pigeon. HE staining. (A) Proventriculus with hemorrhages and edema (arrows); objective magnification $10 \times$. (B) NDV staining in mucous membrane cells of tertiary duct in the proventriculus (arrows); objective magnification $40 \times$. (C) Intestine with necrosis; objective magnification $40 \times$. (D) Kidney infiltration of mononuclear inflammatory cells with necrosis of tubular epithelial cells (arrows); objective magnification $40 \times$. (E) Multifocal lymphoplasmacytic perivascular cuffs in the brain (arrows); objective magnification $40 \times$. (F) NDV protein antigen staining was detected in intracytoplasmic (arrows) and extracellular areas of necrosis neurons (asterisk) of the brain; objective magnification $40 \times$. 
Thirty-four samples (cloacal, oropharyngeal swabs, trachea, and intestine) from 23 pigeons were sent to the Clinical and Molecular Virology Laboratory, Biomedical Sciences Institute, University of São Paulo (LVCM-USP), and LFDA-SP. Cloacal swabs $(\mathrm{n}=22)$, oral swabs $(n=5)$, large intestine $(n=4)$, small intestine $(n=2)$, and trachea $(n=1)$ samples were collected for screening of viral pathogens by molecular tests. All samples were extracted by the MagMax automated method (ThermoFisher) following the manufacturer's guidelines and using the MagMax Total Nucleic acid CORE Purification kit (Thermo Fisher, Carlsbad, CA, USA). Nucleic acids were evaluated by specific real-time RT-PCR (RT-qPCR) for Alphavirus, Flavivirus, West Nile virus, Avian Influenza virus, and Newcastle disease virus, strictly following the referenced protocols [18-22]. The NDV M gene was detected in 27 samples from 19 pigeons, and only four tested birds were negative, comprising seven samples (Table 1). The NDV F gene was detected in 24 samples from 17 pigeons. Twentythree samples were detected by both RT-qPCR targeting M and F genes from 16 pigeons. All samples were negative for the other tested pathogens.

Table 1. Description of collected samples during the NDV outbreak from July to September 2019 in Sao Paulo city, Brazil.

\begin{tabular}{|c|c|c|c|c|c|}
\hline Sample ID & Type of Sample & $\begin{array}{c}\text { Collection } \\
\text { Date }\end{array}$ & Sent to & $\begin{array}{c}\text { Ct Values } \\
\text { NDV M Gene }\end{array}$ & $\begin{array}{c}\text { Ct Values } \\
\text { NDV F Gene }\end{array}$ \\
\hline CCZ001 & CS & $24 / 07 / 2019$ & LVCM-USP & 26.5 & 24.7 \\
\hline CCZ002 & CS & $24 / 07 / 2019$ & LVCM-USP & 18.4 & 29.4 \\
\hline CCZ002 & OS & $24 / 07 / 2019$ & LVCM-USP & 15.1 & 35.3 \\
\hline CCZ003 & $\mathrm{CS}$ & $31 / 07 / 2019$ & LVCM-USP & 19.5 & 27.1 \\
\hline CCZ004 & CS & $05 / 08 / 2019$ & LVCM-USP & 21.6 & Negative \\
\hline CCZ005 & CS & $05 / 08 / 2019$ & LVCM-USP & 22.1 & 30.9 \\
\hline CCZ006 & CS & $05 / 08 / 2019$ & LVCM-USP & 35.1 & Negative \\
\hline CCZ007 & CS & $06 / 08 / 2019$ & LVCM-USP & 20.5 & 28.8 \\
\hline CCZ0030 & LI & 08/08/2019 & FMVZ/LVCM-USP & 23.9 & 29.2 \\
\hline CCZ0031 & CS & $12 / 08 / 2019$ & FMVZ/LVCM-USP & 24.7 & 30.4 \\
\hline CCZ0031 & LI & $12 / 08 / 2019$ & FMVZ/LVCM-USP & 27.4 & 39.9 \\
\hline CCZ0031 & OS & $12 / 08 / 2019$ & FMVZ/LVCM-USP & 28.6 & 34.5 \\
\hline CCZ0031 & TR & $12 / 08 / 2019$ & FMVZ/LVCM-USP & 36.8 & Negative \\
\hline CCZ0032 & CS & $12 / 08 / 2019$ & FMVZ/LVCM-USP & 26.7 & 32.6 \\
\hline CCZ0032 & OS & $12 / 08 / 2019$ & FMVZ/LVCM-USP & Negative & Negative \\
\hline CCZ0033 & CS & $12 / 08 / 2019$ & FMVZ/LVCM-USP & 22.6 & 28.2 \\
\hline CCZ0033 & OS & $12 / 08 / 2019$ & FMVZ/LVCM-USP & 26.8 & 32.1 \\
\hline CCZ0034 & CS & $13 / 08 / 2019$ & FMVZ/LVCM-USP & Negative & Negative \\
\hline CCZ0034 & OS & $13 / 08 / 2019$ & FMVZ/LVCM-USP & Negative & Negative \\
\hline CCZ0035 & CS & $14 / 08 / 2019$ & FMVZ/LVCM-USP & 23.4 & 28.8 \\
\hline CCZ0035 & SI & $14 / 08 / 2019$ & FMVZ/LVCM-USP & 28.9 & 33.9 \\
\hline CCZ0038 & CS & $17 / 08 / 2019$ & LVCM-USP & Negative & Negative \\
\hline CCZ0038 & $\mathrm{LI}$ & $17 / 08 / 2019$ & LVCM-USP & Negative & Negative \\
\hline CCZ0041 & CS & $20 / 08 / 2019$ & LVCM-USP & 27.2 & 32.2 \\
\hline CCZ0041 & SI & $20 / 08 / 2019$ & LVCM-USP & 27.5 & 32.6 \\
\hline CCZ0043 & CS & $20 / 08 / 2019$ & LVCM-USP & 22.0 & 27.9 \\
\hline CCZ0043 & LI & $20 / 08 / 2019$ & LVCM-USP & 22.1 & 27.1 \\
\hline LF1 & $\mathrm{CS}$ & $10 / 09 / 2019$ & LFDA-SP & Negative & 35.6 \\
\hline LF2 & CS & $10 / 09 / 2019$ & LFDA-SP & 19.5 & 32.1 \\
\hline LF3 & CS & $10 / 09 / 2019$ & LFDA-SP & 22.9 & 34.5 \\
\hline LF4 & CS & $10 / 09 / 2019$ & LFDA-SP & Negative & Negative \\
\hline LF5 & CS & $10 / 09 / 2019$ & LFDA-SP & 24.2 & 34.8 \\
\hline LF6 & CS & $10 / 09 / 2019$ & LFDA-SP & 36.9 & Negative \\
\hline LF7 & CS & $10 / 09 / 2019$ & LFDA-SP & 23.1 & 35 \\
\hline
\end{tabular}

$\mathrm{OS}$ = oral swab; $\mathrm{CS}$ = cloacal swab; $\mathrm{LI}=$ large intestine; $\mathrm{TR}=$ trachea; $\mathrm{SM}=$ small intestine, $\mathrm{BR}=$ brain. FMVZ: Faculty of Veterinary Medicine and Animal Health (USP), LVCM: Laboratory of Clinical and Molecular Virology (USP); LFDA-SP: Federal Laboratory for Agricultural Defense in Sao Paulo; LMVPA: Laboratory of Applied Preventive Veterinary Medicine (USP).

Cloacal swab samples from seven pigeons out of twenty-five were collected by the Official Veterinary Service and sent to the Federal Laboratory for Agricultural Defense 
(LFDA-SP), an OIE reference laboratory, for molecular and biological characterization of NDV. Swab samples were pooled within up to four swabs for virus isolation due to the small volume. The obtained isolate was further tested by the hemagglutination inhibition test (HI) and the intracerebral pathogenicity test (ICPI) using the standard methodologies of OIE [5], following the ABNT NBR ISO/IEC 17025 Standard. Briefly, the HI test was performed using reference antisera produced by APHA Scientific and NVSL/APHIS/USDA with a panel of antibodies specific for avian paramyxoviruses (APMV) types - 1 to -9 (except for APMV-5), and the 16 subtypes of the influenza A virus. Additionally, the isolated virus was evaluated against the monoclonal antibodies mAb 7D4 (specific for LaSota vaccine strain), mAb U85 (specific for classical strains), and $\mathrm{mAb} 617 / 161$ (specific for pigeon strains) produced by APHA Scientific. Any HI titer greater than or equal to 16 was considered positive. The ICPI test was performed using $0.05 \mathrm{~mL}$ of the diluted (1:10) isolate by intracerebral route in 10 one-day-old SPF chicks. Birds were kept in isolators and monitored daily for 8 days. Birds were scored as 0 if normal, 1 if sick, or 2 if dead. The mean score per bird per observation over the 8 days was calculated to obtain the ICPI value. The animal experiment and virus isolation were also approved by and performed per IACUC in animal biosecurity level 3 enhanced (ABSL-3E) facilities at LFDA-SP. One isolate was obtained from the pool with samples LF2, LF3, LF5, and LF7. It was inhibited by monoclonal Ab 617/161 with higher titers compared to the other mAbs. Hemagglutination inhibition titers of the isolated virus with the mAb 7D4, U85, and 617/161 were: 8 (uncomplete), 32 (uncomplete), and 512 , respectively. The ICPI index was 0.99 , which is considered virulent.

Total nucleic acid from the oral swab sample CCZ002, named here as NDV / pigeon/SPBrazil/CCZ002/2019, which had the lowest Ct by RT-qPCR targeting the M gene $(\mathrm{Ct}=15.1)$, was reverse-transcribed using SuperScript VILO reverse transcriptase (Thermo Fisher). A second-strand extension was performed using Invitrogen Second Strand cDNA Synthesis Kit (Thermo Fisher). Double-stranded cDNA was purified with Agencourt AMPure XP bead purification (Beckman Coulter, Brea, CA, USA; $1.8 \times$ ratio). Sample dilution and library construction were performed according to the manufacturer's instructions for the Ion Xpress ${ }^{\mathrm{TM}}$ Plus Fragment Library Kit (Thermo Fisher). Individually barcoded libraries (Ion Express Barcode Adapters-Thermo Fisher) were linked with Ion Amplicon Adapter Ligation after AMPure XP bead cleanup $(1.8 \times$ ratio) and before AMPure XP bead cleanup $(1.0 \times$ ratio). The products were size-selected using E-Gel SizeSelect II gels (Thermo Fisher). Amplified libraries were purified (AMPure $\times \mathrm{P}$ bead cleanup $1.0 \times$ ratio) and quantified before pooling using the Ion Library TaqMan Quantitation Kit (Thermo Fisher). The Ion Torrent S5 libraries were prepared using the "Ion 510 ${ }^{\mathrm{TM}} \&$ Ion $520^{\mathrm{TM}} \&$ Ion $530^{\mathrm{TM}} \mathrm{kit}$ " of the Ion Chef Kit for 400 base-read libraries and sequenced on the Ion Torrent S5 using an Ion 530 semi-conductor sequencing chip (Thermo Fisher Scientific, Carlsbad, CA, USA). Obtained raw reads were mapped to reference (KT163264) using Geneious Prime. A consensus sequence with $15,192 \mathrm{bp}$ length had a coverage of $100 \%$ with 111,208 sequencing reads and a mean depth of 2683.5 times. The obtained complete genome of the sample NDV/pigeon/SP-Brazil/CCZ002/2019 was submitted to GenBank under access number MZ458602.

Phylogenetic analysis was performed using the Maximum Likelihood method based on the complete F NDV gene on the General Time Reversible model [23]. Initial tree(s) for the heuristic search were obtained automatically by applying Neighbor-Join and BioNJ algorithms to a matrix of pairwise distances estimated using the Maximum Composite Likelihood (MCL) approach and then selecting the topology with a superior log-likelihood value. A discrete Gamma distribution was used to model evolutionary rate differences among sites $(5$ categories $(+G$, parameter $=0.6753)$ ). The tree was drawn to scale, with branch lengths measured in the number of substitutions per site. The analysis involved 67 nucleotide sequences. Codon positions included were 1st+2nd+3rd+Noncoding. All positions containing gaps and missing data were eliminated. There were a total of 1653 positions in the final dataset. Evolutionary analyses were conducted in MEGA7 [24]. The evolutionary divergence between sequences was conducted using the Maximum Compos- 
ite Likelihood model [25]. The obtained sequence was grouped with sequences from the genotype VI.2.1.2 detected in Africa (Nigeria and Kenya) and South America (Argentina and Brazil) (Figure 2).

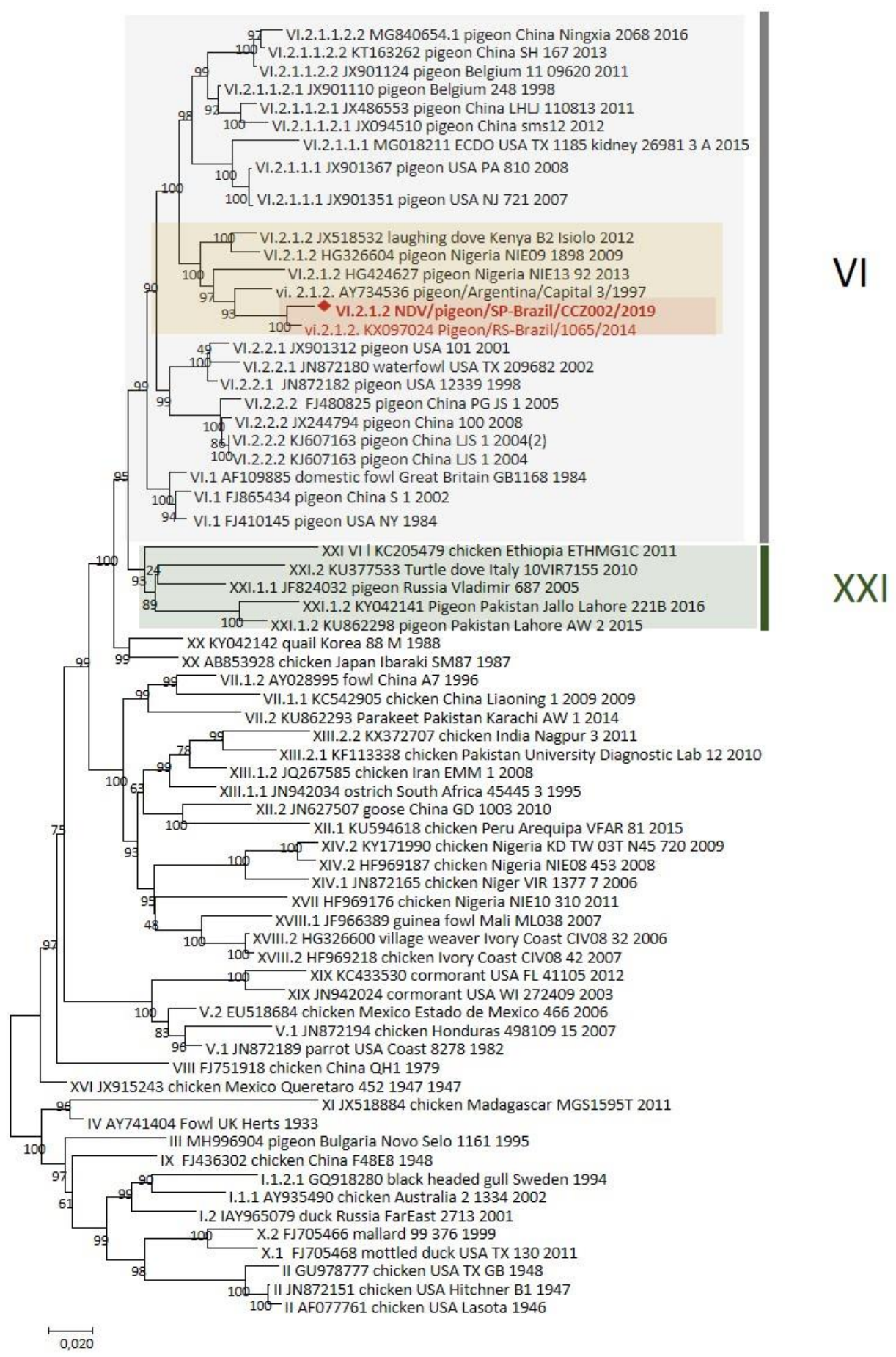

Figure 2. The evolutionary history was inferred by using the Maximum Likelihood method based on complete F NDV gene from the General Time Reversible model [1]. The tree with the highest log likelihood (-20110.81) is shown. The percentage of trees in which the associated taxa clustered together is shown next to the branches. Brazilian samples are highlighted in red, and sequences from the subgenotype VI.2.1.2 are highlighted in yellow. The sequence NDV/pigeon/SP-Brazil/CCZ002/2019 is also highlighted with a red diamond. 
The genetic identities of sequences from the genotype VI.2.1.2 varied from 91.9\% to $97.9 \%$ (Table 2). The obtained sequence in this study had the highest nucleotide identity $(97.9 \%)$, with the sequence from Brazil detected in 2014. Our isolate had three basic amino acids (two arginines and one lysine) between residues 113 and 116 in the C-terminus of the F2 protein and phenylalanine at residue 117 in the N-terminus of the F1 protein (113RQKR $\downarrow$ F117). Such cleavage sites are specific for virulent viruses based on criteria utilized by OIE to assess the virulence of NDV isolates [5].

Table 2. Genetic distances of viruses from subgenotype VI.2.1.2.

\begin{tabular}{ccccccc}
\hline & & & & & ID & \\
\cline { 3 - 7 } ID & Strain Name & $\mathbf{1}$ & $\mathbf{2}$ & $\mathbf{3}$ & $\mathbf{4}$ & $\mathbf{5}$ \\
& & & & & \\
1 & NDV/pigeon/SP-Brazil/CCZ002/2019 & & & & \\
2 & KX097024_Pigeon/RS-Brazil/1065/2014 & 97.9 & & & & \\
3 & AY734536_pigeon/Argentina/Capital_3/1997 & 94.3 & 94.9 & & & \\
4 & JX518532_laughingdove/Kenya/B2/Isiolo/2012 & 92.0 & 92.7 & 94.3 & & \\
5 & HG424627 pigeon/Nigeria/NIE13/92/2013 & 92.7 & 93.4 & 93.7 & 93.8 & \\
6 & HG326604 pigeon/Nigeria/NIE09/1898/2009 & 91.9 & 92.6 & 93.6 & 97.3 & 93.7 \\
\hline
\end{tabular}

\section{Discussion}

The feral pigeons of the present study were found in the metropolitan region of the largest urban center in Latin America. The authorities were notified, and the mitigation actions protocol was initiated. As it is a large urban center, there are no breeding creations in the nearby area. The virus is a serious threat to wild and domestic pigeons with high mortality rates and neurological disorders [4]. In the present study, birds displayed neurological clinical signs with necrosis in multiple organs, as well as histopathological changes.

PPMV-1 is endemic in many countries, and different data support that they do not pose a high threat to the poultry industry [13]. In the current outbreak, 10 chickens (Gallus gallus), which were located close to the sick pigeons, did not show clinical signs (data not shown). Nevertheless, infections with other vNDV genotypes more chicken-adapted have been reported in wild pigeons [26,27]. The last NDV genotype classification split the viruses from genotype VI into a new genotype (XXI) [3]. The genotype XXI can cause clinical signs in chickens without prior adaptation [28]. The diagnostic differentiation using the monoclonal antibodies remains important to distinguish the PPMV-1, especially the subgenotype VI, from other genotypes, but this is not always accessible [7]. Here, a PPMV-1 isolate from subgenotype VI.2.1.2 could be characterized using this panel. The isolate was also classified as a virulent strain by the ICPI test that has an ICPI value greater than 0.7.

The NDV subgenotype VI.2.1.2 was reported in Argentina, Brazil, Nigeria, and Kenya. This subgenotype was previously detected in feral pigeons from a public square in Porto Alegre, the Rio Grande do Sul state, southern Brazil, in 2014 [29]. Although the sequences from Brazil clustered with sequences from Nigeria, Kenya, and Argentina, they have genetic distances greater than 0.05 with a high bootstrap, which suggests that they belong to another subgenotype. However, a new subgenotype can only be suggested with sequences from at least three distinct epidemiological events [3]. The lack of sequences indicates that the notification of diseases in non-commercial birds is limited in Latin American countries, including Brazil.

The present study is the first comprehensive report of the subgenotype V.2.1.2 of NDV detected with biological and molecular characterization. The NDV subgenotype V.2.1.2, initially identified in another urban area in 2014 based on a partial F gene sequence, seemed to continuously circulate in Brazil as it appeared five years later $1100 \mathrm{~km}$ away from its prior identification. Feral pigeon populations with zoonotic pathogens in urban areas can pose a low risk to healthy humans, but this risk can be increased up to 1000 times in immunocompromised patients [30]. PPMV-1 remains zoonotic with generally mild infection in humans, usually conjunctivitis, although two fatal pneumonia cases were already 
reported in immunocompromised persons $[4,16,17]$. Precautious measures should be followed when manipulating wild or domestic animals. According to OIE, 75\% of emerging human pathogens are of animal origin. Thus, the maintenance of active surveillance and the increase in biosafety measures to control pigeon populations away in urban areas and poultry farms are essential.

Author Contributions: Conceptualization, L.M.T., J.A.S., D.B.L.O., T.K.; methodology, L.M.T., J.A.S., D.B.L.O., T.K., H.L.F.; investigation, L.M.T., A.O.T.C., J.A.S., D.B.L.O., T.K., T.C.M.B., E.S., G.C.V.C., D.R., C.M. (Cairo Monteiro), E.G.D., N.U., G.P.S., C.M. (Carla Meneguin), C.W.A., E.L.D., D.R., H.L.F., L.M.N.S., M.V.S.M., L.M.B.; resources, L.M.T., J.A.S., D.B.L.O., D.R., T.K., H.L.F.; data curation, L.M.T., H.L.F.; writing—original draft, L.M.T., A.O.T.C., H.L.F.; writing-review and editing, L.M.T., J.A.S., T.K., D.R., H.L.F.; supervision, E.L.D., H.L.F., L.M.T., D.R.; project administration L.M.T., H.L.F., C.W.A., E.L.D.; funding acquisition, L.M.T., H.L.F., C.W.A., E.L.D. All authors have read and agreed to the published version of the manuscript.

Funding: This research was supported by the FAPESP (2017/01125-2, 2019/13198-0), MCTI-CNPq $(403761 / 2020-4)$.

Institutional Review Board Statement: Sample collection and virus characterization were approved by and performed following the Institutional Animal Care and Use Committee (IACUC) (CEUAFZEA-USP: 1355190521 and CEUA-ICB-USP113/2017). The animal experiment and virus isolation were also approved by and performed per IACUC in animal biosecurity level 3 enhanced (ABSL-3E) facilities at LFDA-SP.

Informed Consent Statement: Not applicable.

Data Availability Statement: The complete genome of the sample NDV/pigeon/SP-Brazil/CCZ002 /2019 described in this work was submitted to GenBank under access number MZ458602.

Acknowledgments: The authors gratefully acknowledge Alessandra Greatti and Julia Cristina Benassi Bueno for their technical assistance.

Conflicts of Interest: The authors declare no conflict of interest.

\section{References}

1. Amarasinghe, G.K.; Ayllon, M.A.; Bao, Y.; Basler, C.F.; Bavari, S.; Blasdell, K.R.; Briese, T.; Brown, P.A.; Bukreyev, A.; BalkemaBuschmann, A.; et al. Taxonomy of the order Mononegavirales: Update 2019. Arch. Virol. 2019, 164, 1967-1980. [CrossRef] [PubMed]

2. Czegledi, A.; Ujvari, D.; Somogyi, E.; Wehmann, E.; Werner, O.; Lomniczi, B. Third genome size category of avian paramyxovirus serotype 1 (Newcastle disease virus) and evolutionary implications. Virus Res. 2006, 120, 36-48. [CrossRef]

3. Dimitrov, K.M.; Abolnik, C.; Afonso, C.L.; Albina, E.; Bahl, J.; Berg, M.; Briand, F.X.; Brown, I.H.; Choi, K.S.; Chvala, I.; et al. Updated unified phylogenetic classification system and revised nomenclature for Newcastle disease virus. Infect. Genet. Evol. 2019, 74, 103917. [CrossRef]

4. Miller, P.J.; Koch, G. Newcastle Disease. In Diseases of Poultry, 13th ed.; Swayne, D., Ed.; John Wiley \& Sons, Inc.: Ames, IA, USA, 2013; pp. 89-107, 120-130.

5. OIE (Ed.) Chapter 3.3.14 Newcastle Disease (infection with Newcastle disease virus). In Manual of Diagnostic Tests and Vaccines for Terrestrial Animals; Biological Standards Commission, World Organization for Animal Health: Paris, France, 2019.

6. Dimitrov, K.M.; Afonso, C.L.; Yu, Q.; Miller, P.J. Newcastle disease vaccines-A solved problem or a continuous challenge? Vet. Microbiol. 2017, 206, 126-136. [CrossRef]

7. Collins, M.S.; Alexander, D.J.; Brockman, S.; Kemp, P.A.; Manvell, R.J. Evaluation of mouse monoclonal antibodies raised against an isolate of the variant avian paramyxovirus type 1 responsible for the current panzootic in pigeons. Arch. Virol. 1989, $104,53-61$. [CrossRef] [PubMed]

8. Ujvari, D.; Wehmann, E.; Kaleta, E.F.; Werner, O.; Savic, V.; Nagy, E.; Czifra, G.; Lomniczi, B. Phylogenetic analysis reveals extensive evolution of avian paramyxovirus type 1 strains of pigeons (Columba livia) and suggests multiple species transmission. Virus Res. 2003, 96, 63-73. [CrossRef]

9. Meulemans, G.; van den Berg, T.P.; Decaesstecker, M.; Boschmans, M. Evolution of pigeon Newcastle disease virus strains. Avian Pathol. 2002, 31, 515-519. [CrossRef] [PubMed]

10. Schuler, K.L.; Green, D.E.; Justice-Allen, A.E.; Jaffe, R.; Cunningham, M.; Thomas, N.J.; Spalding, M.G.; Ip, H.S. Expansion of an exotic species and concomitant disease outbreaks: Pigeon paramyxovirus in free-ranging Eurasian collared doves. EcoHealth 2012, 9, 163-170. [CrossRef] 
11. Bari, F.D.; Gelaye, E.; Tekola, B.G.; Harder, T.; Beer, M.; Grund, C. Antigenic and Molecular Characterization of Virulent Newcastle Disease Viruses Circulating in Ethiopia Between 1976 and 2008. Vet. Med. 2021, 12, 129-140. [CrossRef]

12. Dodovski, A.; Cvetkovikj, I.; Krstevski, K.; Naletoski, I.; Savic, V. Characterization and Epidemiology of Pigeon Paramyxovirus Type-1 Viruses (PPMV-1) Isolated in Macedonia. Avian Dis. 2017, 61, 146-152. [CrossRef]

13. Ferreira, H.L.; Taylor, T.L.; Dimitrov, K.M.; Sabra, M.; Afonso, C.L.; Suarez, D.L. Virulent Newcastle disease viruses from chicken origin are more pathogenic and transmissible to chickens than viruses normally maintained in wild birds. Vet. Microbiol. 2019, 235, 25-34. [CrossRef] [PubMed]

14. Kommers, G.D.; King, D.J.; Seal, B.S.; Brown, C.C. Pathogenesis of chicken-passaged Newcastle disease viruses isolated from chickens and wild and exotic birds. Avian Dis. 2003, 47, 319-329. [CrossRef]

15. Prajna, N.V.; Lalitha, P.; Chen, C.; Zhong, L.; Lietman, T.M.; Doan, T.; Seitzman, G.D. Acute Keratoconjunctivitis Resulting from Coinfection with Avian Newcastle Virus and Human Adenovirus. Cornea 2021. [CrossRef]

16. Kuiken, T.; Breitbart, M.; Beer, M.; Grund, C.; Hoper, D.; van den Hoogen, B.; Kerkhoffs, J.H.; Kroes, A.C.M.; Rosario, K.; van Run, P.; et al. Zoonotic Infection With Pigeon Paramyxovirus Type 1 Linked to Fatal Pneumonia. J. Infect. Dis. 2018, 218, 1037-1044. [CrossRef] [PubMed]

17. Goebel, S.J.; Taylor, J.; Barr, B.C.; Kiehn, T.E.; Castro-Malaspina, H.R.; Hedvat, C.V.; Rush-Wilson, K.A.; Kelly, C.D.; Davis, S.W.; Samsonoff, W.A.; et al. Isolation of avian paramyxovirus 1 from a patient with a lethal case of pneumonia. J. Virol. 2007, 81, 12709-12714. [CrossRef]

18. Wise, M.G.; Suarez, D.L.; Seal, B.S.; Pedersen, J.C.; Senne, D.A.; King, D.J.; Kapczynski, D.R.; Spackman, E. Development of a real-time reverse-transcription PCR for detection of newcastle disease virus RNA in clinical samples. J. Clin. Microbiol. 2004, 42, 329-338. [CrossRef] [PubMed]

19. Sanchez-Seco, M.P.; Rosario, D.; Quiroz, E.; Guzman, G.; Tenorio, A. A generic nested-RT-PCR followed by sequencing for detection and identification of members of the alphavirus genus. J. Virol. Methods 2001, 95, 153-161. [CrossRef]

20. Johnson, N.; Wakeley, P.R.; Mansfield, K.L.; McCracken, F.; Haxton, B.; Phipps, L.P.; Fooks, A.R. Assessment of a novel real-time pan-flavivirus RT-polymerase chain reaction. Vector Borne Zoonotic Dis. 2010, 10, 665-671. [CrossRef] [PubMed]

21. Eiden, M.; Vina-Rodriguez, A.; Hoffmann, B.; Ziegler, U.; Groschup, M.H. Two new real-time quantitative reverse transcription polymerase chain reaction assays with unique target sites for the specific and sensitive detection of lineages 1 and 2 West Nile virus strains. J. Vet. Diagn. Investig. 2010, 22, 748-753. [CrossRef]

22. Zhang, Z.; Liu, D.; Sun, W.; Liu, J.; He, L.; Hu, J.; Gu, M.; Wang, X.; Liu, X.; Hu, S.; et al. Multiplex one-step Real-time PCR by Taqman-MGB method for rapid detection of pan and H5 subtype avian influenza viruses. PLoS ONE 2017, 12, e0178634. [CrossRef]

23. Nei, M.; Kumar, S. Molecular Evolution and Phylogenetics; Oxford University Press: New York, NY, USA, $2000 ;$ p. 333.

24. Kumar, S.; Stecher, G.; Tamura, K. MEGA7: Molecular Evolutionary Genetics Analysis Version 7.0 for Bigger Datasets. Mol. Biol. Evol. 2016, 33, 1870-1874. [CrossRef]

25. Tamura, K.; Nei, M.; Kumar, S. Prospects for inferring very large phylogenies by using the neighbor-joining method. Proc. Natl. Acad. Sci. USA 2004, 101, 11030-11035. [CrossRef]

26. Ferreira, H.L.; Taylor, T.L.; Absalon, A.E.; Dimitrov, K.M.; Cortes-Espinosa, D.V.; Butt, S.L.; Marin-Cruz, J.L.; Goraichuk, I.V.; Volkening, J.D.; Suarez, D.L.; et al. Presence of Newcastle disease viruses of sub-genotypes Vc and VIn in backyard chickens and in apparently healthy wild birds from Mexico in 2017. Virus Genes 2019, 55, 479-489. [CrossRef]

27. Xiang, B.; Chen, L.; Cai, J.; Liang, J.; Lin, Q.; Xu, C.; Ding, C.; Liao, M.; Ren, T. Insights into Genomic Epidemiology, Evolution, and Transmission Dynamics of Genotype VII of Class II Newcastle Disease Virus in China. Pathogens 2020, 9, 837. [CrossRef] [PubMed]

28. Nooruzzaman, M.; Barman, L.R.; Mumu, T.T.; Chowdhury, E.H.; Dimitrov, K.M.; Islam, M.R. A Pigeon-Derived Sub-Genotype XXI.1.2 Newcastle Disease Virus from Bangladesh Induces High Mortality in Chickens. Viruses 2021, 13, 1520. [CrossRef]

29. Souza, S.P.; Fredo, G.; Dupont, P.; Leite-Filho, R.; Pavarini, S.C.C.; Driemeier, D. Pathological and molecular findings of avian avulavirus Type 1 outbreak in pigeons (Columba livia) of southern Brazil. Pesqui. Vet. Bras. 2018, 38, 2254-2261. [CrossRef]

30. Haag-Wackernagel, D.; Moch, H. Health hazards posed by feral pigeons. J. Infect. 2004, 48, 307-313. [CrossRef] [PubMed] 